Available online at Dakwah: Jurnal Kajian Dakwah dan Kemasyarakatan http://journal.uinjkt.ac.id/index.php/dakwah

Dakwah: Jurnal Kajian Dakwah dan Kemasyarakatan, 23 (2), 2019, 64-84

\title{
Strategi Pengembangan Prodi Pengembangan Masyarakat Islam (PMI) Fidkom Uin Syarif Hidayatullah Jakarta dalam Menghadapi Masyarakat Ekonomi Asean (Mea) \\ Nurul Hidayati, S.Ag., M.Pd \\ FIDKOM UIN Syarif Hidayatullah Jakarta nurul.hidayati@Uinjkt.ac.id
}

\begin{abstract}
The purpose of this study is to obtain an overview of the strategies used by the Islamic Community Development (PMI) Department at Fidkom UIN Syarif Hidayatullah Jakarta in facing the AEC (ASEAN Economic Community) using the Strategy-Formulation Analytical Framework. The approach is quantitative. An interesting strategy from the results of this study is the intensive strategy, in accordance with the results of the analysis of information about the condition of PMI Fidkom UIN Syarif Hidayatullah Jakarta which is suggested to use an intensive strategy. In the information analysis, the condition of the PMI Department is in Quadrant II or is experiencing growth. However, the PMI Department is in the environment of strong competition so it is hoped that PMI can implement an intensive strategy that seeks to increase market share by prioritizing student achievement, excellent service, and a good curriculum.
\end{abstract}

Keyword : strategic, FGD, threat, strength

\begin{abstract}
Abstrak
Tujuan penelitian ini adalah untuk mendapatkan gambaran strategi yang digunakan oleh Program Studi Pengembangan Masyarakat Islam (PMI) di Fidkom UIN Syarif Hidayatullah Jakarta dalam menghadapi MEA (Masyarakat Ekonomi ASEAN) dengan menggunakan Strategy-Formulation Analytical Framework. Pendekatannya adalah kuantitatif. Strategi yang menarik dari hasil penelitian ini adalah strategi intensif, sesuai dengan hasil analisis informasi tentang kondisi PMI Fidkom UIN Syarif Hidayatullah Jakarta yang disarankan untuk menggunakan strategi intensif. Pada analisis informasi, kondisi Program Studi PMI berada pada Kuadran II atau sedang mengalami tumbuh kembang. Namun Program Studi PMI tengah berada dalam lingkungan persaingan yang kuat sehingga diharapkan PMI dapat menerapkan strategi intensif yang berupaya meningkatkan pangsa pasar dengan cara mengedepankan prestasi mahasiswa, pelayanan prima, dan kurikulum yang baik.

Kata kunci: strategi, FGD, ancaman, kekuatan
\end{abstract}

Permalink/DOI: http://doi.org/10.15408/dakwahv23i2.13937 


\section{Pendahuluan}

Persaingan di bursa tenaga kerja, tampaknya akan semakin meningkat menjelang pemberlakuan pasar bebas Asean yang dikenal dengan sebutan Masyarakat Ekonomi Asean (MEA) yang dimulai dari tahun 2015 hingga saat ini. Hal ini menimbulkan tren, yaitu 'gaya-mutakhir' yang sangat mempengaruhi para pekerja yang berkecimpung pada sektor keahlian khusus. Berkaitan dengan hal tersebut itu maka para pemimpin Asean sepakat membentuk sebuah pasar tunggal di kawasan Asia Tenggara pada akhir tahun 2015 mendatang ${ }^{1}$. Program Studi/Jurusan Pengembangan Masyarakat Islam (PMI) Fakultas Ilmu Dakwah dan Ilmu Komunikasi UIN Syarif Hidayatullah Jakarta, yang merupakan lembaga pendidikan yang memiliki visi untuk menjadi lembaga yang mampu menyediakan sumber daya professional di bidang pengabdian masyarakat dengan masyarakat Islam sebagai ranah uji ${ }^{2}$, dipengaruhi pula dengan adanya Masyarakat Ekonomi Asean (MEA).

Berkaitan dengan hal itu, maka muncullah wacana yang diungkapkan oleh dosen di beberapa pertemuan dan di media sosial bahwa Program Studi Pengembangan Masyarakat Islam sebaiknya diganti menjadi Program Studi Pembangunan. Alasannya adalah karena berdasarkan kebutuhan di lapangan -- terutama dalam menghadapi MEA (Masyarakat Ekonomi Asean) -- dan jejaring kerja ilmu pengetahuan global, dimana social development ada di berbagai Universitas di Dunia.

Selain itu pula jumlah mahasiswa PMI di seluruh Indonesia termasuk ke dalam langka peminat, atau mengalami krisis jumlah yang rata-rata hanya memiliki 1 kelas dengan jumlah yang paling banyak 30 kelas. Bahkan ada pula yang berjumlah 16 Mahasiswa -- Workshop Kurikulum Pengembangan Masyarakat Indonesia (PMI) yang diselenggarakan oleh APMI (Asosiasi Pengembangan Mayarakat Islam) se-Indonesia di Hotel Citra Dream Jakarta Tanggal 26 Mei 2016 --.

Padahal menurut Prof. Soesetyawan (Guru Besar UGM) dalam pembahasan kurikulum Studi Pembangunan Sosial yang diselenggarakan oleh Asosiasi Pembangunan Sosial Indonesia (APSI) seIndonesia di Fakultas Ilmu Dakwah dan Ilmu Komunikasi UIN Syarif Hidayatullah Jakarta Tanggal 25 Mei 2016 sempat memuji kurikulum yang disusun oleh Jurusan Pengembangan Masyarakat Islam (PMI) UIN Jakarta.

Tujuan Penelitian ini adalah memperoleh gambaran tentang posisi, serta strategi yang layak dan yang memiliki daya tarik (yang paling berpengaruh) yang dapat digunakan oleh Jurusan PMI Fidkom UIN Syarif Hidayatullah Jakarta dalam menghadapi MEA (Masyarakat Ekonomi Asean) / EAC (Economic Asean Community), dengan menggunakan Kerangka Analisis Penyusunan Strategi (The Strategy-Formulation Analytical Framework).

\section{KAJIAN TEORI}

David dalam bukunya Strategic Management Concepts and cases menyatakan, strategi sebuah perusahaan baik yang besar dan kecil sangat menentukan kemajuan perusahaannya3. 
Strategi dalam buku Hitt, Strategic input stage (Tahap pengumpulan Management Consepts \& Cases informasi), tahap kedua the matching stage

Tabel 1

Kerangka Analisis Penyusunan Strategi (The StrategyFormulation Analytical Framework)

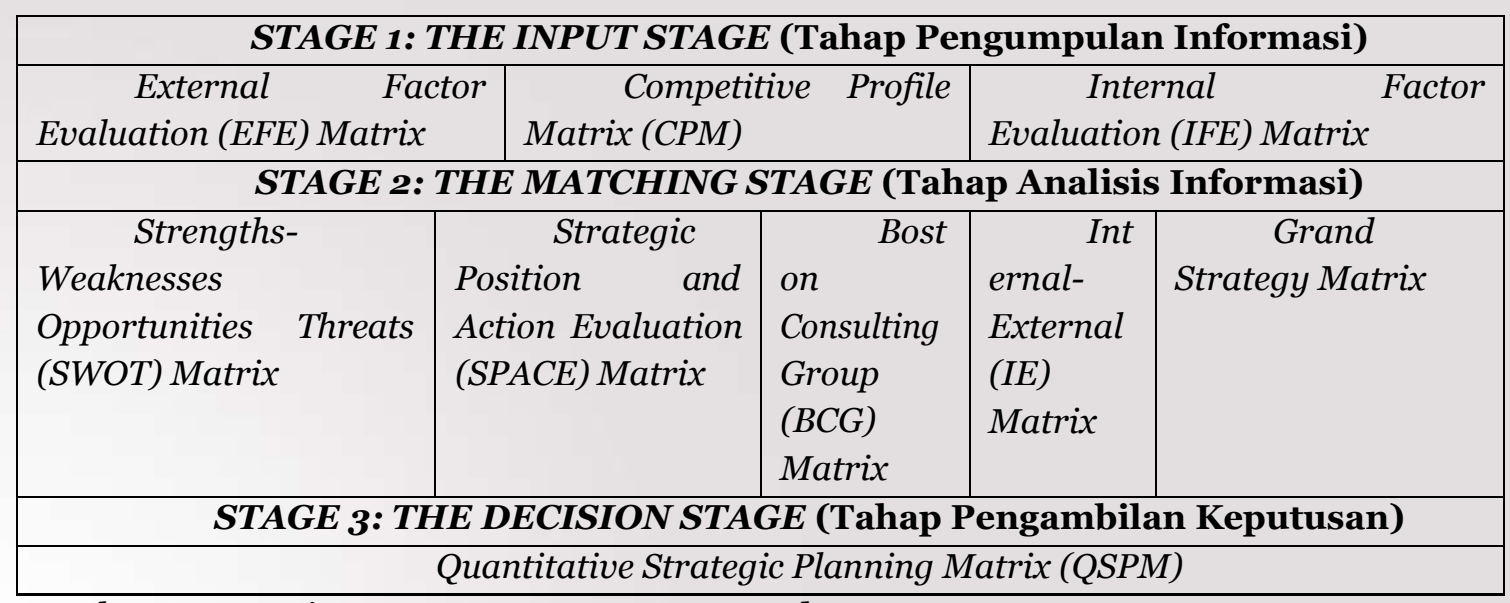

Sumber: Strategic Management Consepts and Casess

Competitiveness and Globalization adalah aksi sebuah perusahan yang diawali dengan berbagai komitmen yang terpadu dan disusun dengan mengerahkan kompetensi yang ada supaya unggul dalam persaingan ${ }^{4}$.

Tidak hanya perusahaan, lembaga pendidikan tinggi di Indonesia pun saat akreditasi diwajibkan menyusun strategi Jurusan, Fakultas bahkan Perguruan Tinggi berdasarkan analisis SWOT. Akreditasinya dilakukan oleh BAN PT (Badan Akreditasi Nasional Perguruan Tinggi).

David memberikan gambaran tentang Kerangka Analisis Perumusan Strategi Kerangka Analisis Penyusunan Strategi (The Strategy-Formulation Analytical Framework) yang ada pada tabel 1.

David memberikan tiga tahap dalam merumuskan strategi. Tahap pertama the
(Tahap analisis), tahap ketiga tahap the decision stage (Tahap pengambilan keputusan).

Pada tahap pengumpulan informasi dilakukan penggalian informasi untuk dimasukkan ke dalam tahap analisis dan tahap pengambilan keputusan. Informasi dikumpulkan dengan cara mengevaluasi faktor dari luar (External Factor Evaluation (EFE) Matrix) dengan melihat peluang dan ancaman, serta faktor dari dalam (Internal Factor Evaluation (IFE) Matrix) dengan melihat kelebihan dan kekurangan perusahaan yang ingin merancang strategi. Sedangkan Matriks Profil Kompetitif (CPM) mengevaluasi kekuatan dan kelemahan perusahaan yang menjadi saingan bagi perusahaan yang akan menyusun strategi. 
Penelitian ini hanya menggunakan EFE dan IFE dikarenakan sulit bagi peneliti untuk mencari informasi tentang jurusan PMI. Tidak berarti Jurusan PMI FIDKOM UIN Syarif Hidayatullah Jakarta merupakan Jurusan PMI yang terbaik di antara Jurusan PMI di Perguruan Tinggi lainnya, namun karena penelitian ini membatasi hanya pada Jurusan PMI Fidkom UIN Syarif Hidayatullah Jakarta. Sementara itu, yang dikaji pada Matriks Profil Kompetitif (CPM) yaitu kelemahan dan kelebihan pada Jurusan PMI di Perguruan Tinggi lain yang menjadi pesaing Jurusan PMI Fidkom UIN Syarif Hidayatullah Jakarta.

Pada tahap 2: The Matching stage dilakukan pencocokan informasi yang ada pada tahap 1, informasi faktor dari luar (external factor) peluang dan ancaman dengan informasi faktor dari dalam (internal factor) kekuatan dan kelebihan sehingga melahirkan strategi alternatif. Hasilnya dianalisis dengan beberapa teknik analisis seperti Strengths-Weaknesses Opportunities Threats (SWOT) Matrix, The Strategic Position and Action Evaluation (SPACE) Matrix, The Boston Consulting Group (BCG) Matrix, The Internal-External (IE) Matrix, dan The Grand Strategy Matrix.

Pada tahap 2 penelitian Pengembangan Strategi Jurusan PMI FIDKOM UIN Syarif Hidayatullah Jakarta dalam menghadapi masyarakat Ekonomi Asean (MEA) menggunakan teknik analisis Strengths-Weaknesses Opportunities Threats (SWOT) Matrix dan The InternalExternal (IE) saja. Kedua teknik tersebut digunakan karena teknik SWOT merupakan kelanjutan dari EFE Matrix dan IFE Matrix.
Sementara The Strategic Position and Action Evaluation (SPACE) Matrix, The Boston Consulting Group (BCG) Matrix, dan The Grand Strategy Matrix merupakan kelanjutan dari Competitive Profile Matrix $(C P M)^{5}$.

Tabel 2

\section{MATRIK TOWS/SWOT}

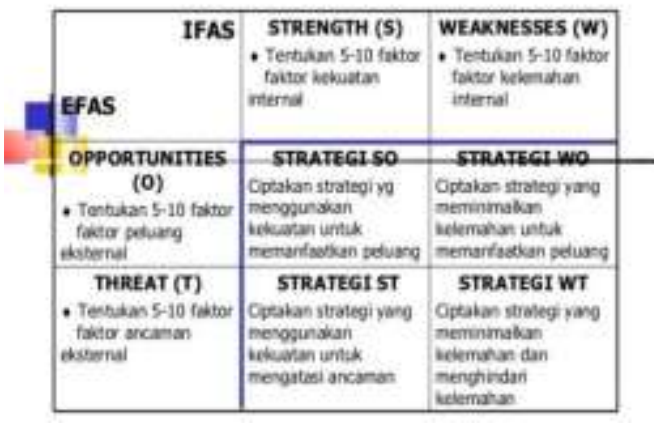

Sumber

https://www.slideshare.net/Eristo n/analisis-swot-10628596

Pada teknik Strengths-Weaknesses Opportunities Threats (SWOT) Matrix dilakukan pencocokan antara EFE dan IFE untuk melahirkan strategi alternatif yang efektif bagi perusahaan. Hal ini dikarenakan strategi yang dirancang berdasarkan pemanfaatan kekuatan untuk mengambil peluang (SO), pemanfaatan kekuatan untuk mengatasi ancaman (ST), meminimalisir kelemahan dengan mengambil peluang (WO), dan meminimalisir kelemahan untuk mengatasi ancaman (WT) ${ }^{6}$.

Setelah itu Matrik Internal-Eksternal (Internal-External (IE) Matrix) digunakan untuk menganalisa apakah posisi perusahaan dalam kondisi pertumbuhan atau penciutan, stabilitas atau penciutan, dan atau pertumbuhan atau likuidasi7.

Gambar 1 
Matrik Internal-

Eksternal (Internal-External (IE) Matrix)

Sumber;

Strategic

Management Concepts and cases

Thirteenth edition Fred. David

Sel I, II, dan IV adalah kuadran wilayah tumbuh dan berkembang. Sel III, V, dan VII merupakan kuadran wilayah pengelolaan yang baik dengan strategi bertahan dan mempertahankan, sel VI, VIII, atau IX adalah likuidasi atau bangkrut.

Menurut David (2011, 192) Bahwa posisi perusahaan/lembaga yang berada di Kuadran II berada di posisi tumbuh atau berkembang namun berada di persaingan yang kuat dan cepat. Untuk itu diharapkan untuk mengevaluasi dan pangsa pasar dan menentukan suatu pendekatan agar dapat bersaing secara efektif. Strategi yang terbaik yang digunakan adalah strategi intensif.

Sementara itu untuk posisi kuadran III bersaing dalam lingkungan pertumbuhan lambat dan memiliki kompetitif yang lemah. Dengan demikian diharapkan melakukan perubahan drastis dengan cepat untuk menghindari penurunan lebih lanjut dan kemungkinan likuidasi. Pengurangan biaya dan pengurangan biaya yang berlebihan (penghematan) harus diupayakan terlebih dahulu. Strategi alternatif adalah mengalihkan sumber daya dari bisnis saat ini ke berbagai wilayah (diversifikasi). Jika semuanya gagal, opsi terakhir untuk bisnis Quadrant III adalah bangkrut atau likuidasi.

Posisi kuadrant IV memiliki posisi kompetitif yang kuat namun berada dalam industriyang lamban. Perusahaanperusahaan ini memiliki kekuatan untuk melahirkan program yang terdiversifikasi ke dalam area pertumbuhan yang lebih menjanjikan: Perusahaan kuadran IV memiliki tingkat arus kas yang khas dan kebutuhan pertumbuhan internal yang terbatas dan seringkali dapat mengejar diversifikasi yang terkait atau tidak terkait dengan sukses. Kuadran IV perusahaan juga dapat mengejar usaha patungan.

Namun sebelum melakukan Matrik Internal-Eksternal (Internal-External (IE) Matrix) terlebih dahulu analisis strategi Jurusan PMI bedasarkan matrik faktor strategi internal atau IFAS (Internal Strategic Factor Analisis Summary) matrik dan faktor strategi eksternal EFAS (Eksternal Strategic Factor Analisis Summary) ${ }^{8}$.

Pada tahap 1 dan 2 menghasilkan strategi alternatif yang layak. Lalu diberi bobot 1 sampai dengan 4 sebagai tanda prioritas terhadap strategi alternatif yang layak. Selanjutnya di tahap 3 yaitu tahap pengambilan keputusan dilakukan penentuan daya tarik dari strategi yang layak dan prioritas yang telah dianalisis sebelumnya di tahap 1 dan 2.

Selain strategi peringkat untuk mencapai daftar prioritas, hanya ada satu teknik analisis dalam literatur yang dirancang untuk menentukan daya tarik relatif dari kemungkinan tindakan alternatif. Pada tahap ketiga ini digunakan Teknik The Quantitatif Strategic Planning Matrix (QSPM) 9 .

Pada penelitian Pengembangan Strategi Jurusan PMI Fidkom UIN Syarif Hidayatullah Jakarta dalam pengambilan keputusan akan digunakan QSPM, sebab sejalan dengan analisis SWOT. 
Pada Karakteristik dan Elemen Economic Asean Community (EAC)/(MEA) mengenai Pasar Tunggal dan Basis Produksi pada poin 5 tertulis 'arus bebas tenaga kerja terampil'.10 Tindakan untuk mencapai poin tersebut yaitu, memfasilitasi penerbitan visa dan ijin kerja, peningkatan mobilitas siswa, dan mempromosikan keterampilan, penempatan kerja, dan pengembangan jaringan informasi pasar tenaga kerja.11 Begitu seriusnya AEC sehingga ada upaya untuk mempermudah agar pasar tunggal dan basis produksi tercapai.

Keseriusan tersebut membuahkan hasil dengan adanya salah satu kemajuan yang telah dicapai oleh Masyarakat Ekonomi Asean (MEA)/(EAC), adanya aliran tenaga kerja terampil untuk layanan teknik, praktisi medis, dokter gigi, layanan keperawatan, arsitek, surveyor, dan akuntan. $^{12}$ Hal ini tidak menutup kemungkinan akan ada pertukaran tenaga kerja lainnya.

Dalam hal perdagangan barang, MEA/EAC sangat memperhatikan atau mempermudah Usaha Mikro Kecil Menengah (UMKM) dengan dihapuskannya biaya masuknya barang dan menghilangkan atau mengurangi peraturan perbatasan serta hambatan-hambatan perdagangan lainnya sehingga menjadi lebih mudah lagi pendistribusian barang di berbagai wilayah ${ }^{13}$.

Terkait hal tersebut, cita-cita MEA/EAC sejalan dengan tujuan program Jurusan PMI Fidkom UIN Syarif Hidayatullah Jakarta yaitu, pengembangan ekonomi yang menghasilkan lulusan yang mampu menganalisis dan menanggulangi masalah-masalah sosial dengan pendekatan pemberdayaan masyarakat, yaitu dengan jalan mengembangkan potensi sumber daya insani, sumberdaya lingkungan, dan pengembangan ekonomi. ${ }^{14}$

Kemampuan mengembangkan ekonomi alumni diperoleh dari materi perkuliahan yang terdistribusikan dalam mata kuliah seperti mata kuliah Manajemen Lembaga Keuangan Ummat Manajemen Community Organizer, Pengembangan Kelembagaan Lokal, Pengembangan UKM dan Koperasi, Kewirausahaan, Pengantar Manajemen, dan Pengantar Ekonomi ${ }^{15}$. Namun apakah dengan berbekal materi yang berkaitan ekonomi serta bahasa asing sudah mencukupi untuk menghadapi MEA/EAC dimasa mendatang?

Kajian terdahulu penelitian ini yaitu adanya survey kepuasan mahasiswa dan evaluasi diri di setiap penyusunan borang. Survey tersebut sangat berbeda dengan survey yang akan dilakukan pada penelitian ini karena survey kepuasan terdahulu hanya untuk penyusunan borang untuk memenuhi persyaratan akreditasi saja. Sementara itu pada penelitian ini survey kepuasan dijadikan sebagai bahan untuk mengetahui efektifitas program dengan analisa model Kirkpatrick.

Hasil evaluasi diri terdahulu juga dilakukan untuk penyusunan borang akreditasi Jurusan PMI. Dimana penyusunan tersebut hanya bersumber dari interview saja. Sementara evaluasi diri pada penelitian ini bukan hanya sekedar hasil interview tapi merupakan hail Focus Group Discussion dengan memberi peringkat pada evaluasi diri tersebut berdasarkan kesepakatan bersama, dan hasilnya dianalisis menggunakan matrik SWOT 
sehingga dapat diketahui posisi PMI di dunia pendidikan dan dapat dijadikan sebagai analisis kebutuhan untuk menyusun strategi PMI.

\section{METODOLOGI PENELITIAN}

Tempat pelaksanaan pengumpulan data di ruang rapat Dosen di Lantai Dasar Fakultas Ilmu Dakwah dan Ilmu Komunikasi UIN Syarif Hidayatullah Jakarta yang beralamatkan Jl. Ir. H. Juanda no. 95 FIDKOM UIN Syarif hidayatullah Jakarta Kode Pos 15412.

Ruang dengan 1 AC 1 PK dengan kedinginan 16, berkapasitas 20 orang, ruangan berbentuk persegi panjang, dengan alat media infokus serta white board, berkursi dan meja yang didisain mewah, berwarna coklat. Orang-orang yang terlibat atau berada dalam ruang pengambilan data, 20 orang informan, Peneliti, dan Office Boy, serta 3 orang pembantu peneliti.

Metode penelitiannya cara observasi terfokus. Artinya, peneliti mengamati peserta diskusi dengan memfokuskan pada variable-variabel yang akan didiskusikan dan disepakati pada kelompok Focus Group Discussion (FGD) sejak awal hingga akhir diskusi. Peneliti bersikap sebagai mediator saja, sementara informan yang berperan aktif berdiskusi dan bermusyawarah untuk menentukan variable-variabel yang sudah ditentukan sebelumnya.

Teknik pengumpulan datanya menggunakan Focus Group Discussion (FGD). Aliran penelitian ini adalah interaksi simbolik, peneliti mengamati interaksi antar individu saat berdiskusi dan bermufakat tentang beberapa variabel. Harapannya adalah dalam FGD tiap individu konsep dirinya dapat berkembang dikarenakan adanya interaksi sehingga membentuk motif yang mempengaruhi perilaku tiap individu. Seperti seperti yang dijelaskan oleh Wikipedia(2016) bahwa La Rossan menjelaskan, perilaku seseorang terbentuk dari motif berdasarkan konsep diri yang dikembangkan oleh interaksi antar individu.

Pada penelitian ini diharapkan mahasiswa memiliki konsep diri sehingga lebih memahami kondisi jurusannya yaitu jurusan PMI, sehingga memiliki motif kuat untuk turut serta dalam mengembangkan Jurusan PMI. Jenis penelitian ini adalah penelitian evaluasi dimanadi dalam penelitian ini diawali dengan penilaian diri yang dilakukan oleh Jurusan PMI dengan melihat kekuatan, kelemahan, peluang, dan ancaman pada diri Jurusan PMI. Informan yang digunakan sebanyak 20 puluh orang yang terdiri 10 mahasiswa dan 10 orang alumni yang lulus di tahun 2017.

Prosedur pengolahan datanya yaitu menggabungkan hasil diskusi Focus Group Discussion (FGD) yang dilakukan mahasiswa dengan yang dilakukan alumni Jurusan PMI. Jika ada data yang serupa maka akan dipilih salah satu data saja sebagai perwakilan dari data yang sama.

Teknik pemeriksaan keabsahan data digunakan untuk melihat kebenaran atau keabsahan data yang diperoleh oleh peneliti. Ada beberapa cara di antarannya memperpanjang masa pengamatan, melakukan pengamatan secara terus menerus. Semakin lama mengamati dan secara terus menerus maka datanya semakin absah dan semakin tinggi derajat kepercayaan data tersebut. Dalam hal ini peneliti melakukan FGD sebanyak 3 hari 
berturut-turut. Dari jam 8.00 sampai dengan jam 16.0o.

Teknik lainnya yaitu menggunakan Triangulasi yaitu memanfaatkan salah satu sumber dari 3 sumber. Pertama yaitu pemanfaatan sumber dari informan, atau kedua pemanfaatan sumber dari teknik pengumpulan data, atau ketiga pemanfaatan sumber dari referensi buku atau para pakar. Saat melakukan FGD terjadi triangulasi antar informan karena mereka bermusyawarah untuk menyepakati strategi yang layak dan yang memiliki daya tarik dari yang tinggi hingga yang rendah dengan menggunakan Kerangka Analisis Penyusunan Strategi (The StrategyFormulation Analytical Framework).

Teknik analisis datanya yaitu menggunakan Kerangka Analisis Penyusunan Strategi (The StrategyFormulation Analytical Framework) melalui FGD. Aktifitas yang dilakukan saat FGD yaitu memusyawarahkan kekuatan (strenght), kelemahan (Weakness), Peluang (opportunity), dan ancaman (threat) Jurusan PMI dari untuk memenuhi tahap pengumpulan data dengan menggunakan External Factor Evaluation (EFE) Matrix.

Setelah itu memusyawarahkan strategi jurusan PMI Fidkom UIN Syarif Hidayatullah Jakarta dengan memanfaatkan kekuatan guna mengambil peluang (Strenght Opportunity (SO)), memanfaatkan kekuatan guna menghadapi ancaman (Strenght Threat (ST)), meminimalisir kelemahan dengan mengambil peluang (Weakness Opportunity (WO)), meminimalisir kelemahan guna menghadapi ancaman (Weakness Threat (WT)). SO, ST, WO, dan WT dimanfaatkan untuk teknik analisis informasi StrengthsWeaknesses-Opportunities-Threats

\section{(SWOT) Matrix.}

Kemudian peserta memusyawarahkan Strategi Jurusan PMI berdasarkan matrik faktor strategi internal atau IFAS (Internal Strategic Factor Analisis Summary) matrik dan faktor strategi eksternal EFAS (Eksternal Strategic Factor Analisis Summary). Setelah itu memusyawarahkan pembobotan dan penentuan rating, mengalikan bobot dan rating, guna menentukan kondisi Jurusan PMI Fidkom UIN Syarif Hidayatullah Jakarta apakah kondisi pertumbuhan, stabil, penciutan ataukah likuidasi untuk memenuhi tahap 3 analisis data dengan teknik Interl-external (IE) Matrix.

Terakhir memusyawarahkan strategi yang memiliki daya tarik dari yang tertinggi hingga terendah dengan menggunakan Matrik Perencanaan Strategi Kuantitatif Quantitative Strategic Planning Matrix (QSPM) guna memenuhi tahap terakhir yaitu tahap 3; Pengambilan Keputusan.

\section{PEMBAHASAN}

Penelitian pengembangan strategi Jurusan PMI Fidkom UIN Syarif Hidayatullah Jakarta dalam menghadapi MEA (Masyarakat Ekonomi Asean) menggunakan Kerangka Analisis Penyusunan Strategi (The StrategyFormulation Analytical Framework). Kerangka Analisis Penyusunan Strategi (The Strategy-Formulation Analytical Framework) terdiri dari 3 tahap yaitu, tahap pertama pengumpulan informasi, tahap kedua analisis informasi, dan tahap ketiga pengambilan keputusan. Tahap 
pertama akan dijelaskan Sub judul Temuan penelitian, sedangkan tahap kedua dan ketiga akan dibahas pada sub judul pembahasan hasil penelitian.

Hasil pengumpulan informasi pada tahap kesatu dengan cara mengevaluasi faktor-faktor dari luar (External Factor Evaluation (EFE)), pertama peluang (opportunty) terdiri dari, banyaknya peluang kerjasama dengan lembaga lain, peluang merekrut mahasiswa sangat besar terlihat dari adanya peminat mahasiswa yang tinggi, alumni dapat bekerja di berbagai sektor dan instansi, LSM baik yang pemberdayaan maupun yang bukan pemberdayaan serta dapat mendirikan Lembaga sendir, kedua adalah ancaman (Threat), minimnya kerjasama antar jurusan, persaingan dengan jurusan PMI perguruan tinggi lain, PMI kurang dikenal.

Hasil pengumpulan informasi dengan cara mengevaluasi factor-faktor dari dalam (Internal Factor Evaluation (IFE)), pertama yaitu kekuatan (strenght) terdiri dari dosen expert di bidangnya, dosen memiliki pengalaman yang baik di bidangnya, kredibilitas dosen sangat baik, metode mengajar dosen menarik, kurikulum sangat bagus jika dibandingkan dengan kurikulum IPB, pelayanan selalu memberikan solusi, biaya kuliah termasuk murah. Kedua yaitu kelemahan (weakness) terdiri dari kurangnya kerjasama antara HMJ dengan Jurusan, kurangnya penguasaan bahasa asing pada mahasiswa, minimnya kreativitas mahasiswa, sarana dan prasarana kurang lengkap (pustaka dan kelas), mahasiswanya sedikit, motivasi mahasiswa rendah, tidak ada sosialisasi jurusan.
Pengumpulan informasi tentang faktor strategi dari dalam (Internal Strategic Factor Analisis Summary (IFAS)) dan faktor strategi dari luar (Eksternal Strategic Factor Analisis Summary(EFAS)) nantinya akan digunakan pada analisis informasi yang layak dan yang memiliki daya tarik dengan menggunakan matrik kekuatan - kelemahan - peluang ancaman (Strengths - Weaknesses Opportunities - Threats (SWOT) Matrix).

Pada matrik tersebut akan terbentuk strategi yang layak yaitu, strategi kekuatanpeluang (Strenght-Opportunity (SO) yang memanfaatkan kekuatan untuk dapat mengambil peluang yang ada. Kemudian terbentuk pula strategi yaitu, strategi kelemahan-peluang (WeaknessOpportunity (WO)) dengan meminimalisir kelemahan untuk mengambil peluang. Selain itu pula akan terbentuk strategi kekuatan-ancaman (Strenght-Threat (ST)). Terakhir akan terbentuk strategi kelemahan-ancaman (Weakness-Threat (WT)).

Pada tahap 2 teknik analisis informasi yang digunakan yaitu dengan matrik kekuatan-kelemahan-peluang-ancaman (Strengths-Weaknesses-OpportunitiesThreats (SWOT) Matrix), dan matrik dalam dan luar (Internal-External (IE) Matrix).

Strategi yang layak digunakan oleh Jurusan PMI Fidkom UIN Syarif Hidayatullah Jakarta dalam menghadapi MEA (Masyarakat Ekonomi Asean) berdasarkan Kerangka Analisis Penyusunan Strategi (The Strategy-Formulation Analytical Framework).

Hasil analis informasi dengan menggunakan matrik kekuatan - Peluang 
(Strengths - Opportunities), terbentuklah strategi SO (Strenght, Opportunity), mengadakan kerjasama dengan lembaga, Instansi, perusahaan dan lainnya untuk mendapatkan peluang kerja dan untuk mengembangkan jurusan, pemberian beasiswa terhadap mahasiswa PMI, diadakan pertukaran pelajar, dan melakukan pemberdayaan bagi mahasiswa.

Strategi SO terbentuk karena untuk pemanfaatan kekuatan dosen yang expert dan berpengalaman di bidangnya, serta kredibilitasnya yang sangat baik, dan metode mengajarnya yang menarik dan untuk mengambil peluang banyaknya peluang kerjasama dengan lembaga lain, dan alumni dapat bekerja di berbagai sektor, instansi, LSM baik yang pemberdayaan maupun yang bukan pemberdayaan serta dapat mendirikan lembaga sendiri (O1 dan O3).

Hasil analisis informasi dengan menggunakan matrik kelemahan - peluang (Weakness - Opportunities), terbentuklah strategi WO (Weakness - Opportunities), a. Membuat kerjasama secara kesinambungan karena untuk meminimalisir kelemahan (Weakness (W)) kurangnya kerjasama antara HMJ dengan Jurusan untuk mengambil peluang (Opportunity (O)) banyaknya peluang kerjasama dengan lembaga lain, b. Pelaksanaan intensif bahasa asing dengan pusat bahasa UIN (sort course) karena untuk meminimalisir kelemahan (Weakness (W)) kurangnya penguasaan bahasa asing pada mahasiswa dengan mengambil peluang (Opportunity (O)) banyaknya peluang kerjasama dengan lembaga lain.
Strategi WO (Weakness-Opportunity) yang lainnya yaitu, c. Pembuatan desa binaan yang dikelola oleh mahasiswa dan alumi PMI karena untuk meminimalisir kelemahan (Weakness (W)) minimnya kreativitas mahasiswa, sarana dan prasarana yang kurang banyak (pustaka dan kelas), motivasi mahasiswa rendah dengan mengambil peluang (Opportunity (O)) alumni dapat bekerja di berbagai sektor, instansi, LSM baik yang pemberdayaan maupun yang bukan pemberdayaan serta dapat mendirikan lembaga sendiri.

Selain itu strategi WO (Weakness Opportunities) lainnya adalah $\mathrm{d}$. memfasilitasi Mahasiswa dengan Workshop Social Entrepreneur untuk meminimalisir kelemahan (Weakness (W)) minimnya kreativitas mahasiswa, sarana dan prasarana yang kurang banyak (pustaka dan kelas), dan motivasi mahasiswa rendah untuk mengambil peluang (Opportunity (O)) alumni dapat bekerja di berbagai sektor, instansi, LSM baik yang pemberdayaan maupun yang bukan pemberdayaan serta dapat mendirikan lembaga sendiri.

Terakhir strategi WO lainnya adalah, e. Perlunya pertemuan Alumni dan Mahasiswa serta Jurusan secara berkala untuk meminimalisir kelemahan (Weakness (W)) minimnya kreativitas mahasiswa, motivasi mahasiswa rendah, tidak ada sosialisasi Jurusan ke luar, dengan mengambil peluang (Opportunity (O)) alumni dapat bekerja di berbagai sektor, instansi, LSM baik yang pemberdayaan maupun yang bukan pemberdayaan serta dapat mendirikan lembaga sendiri, $f$. Pengembangan masyarakat ke sekolah 
(ComDev Goes To School) dengan meminimalisir kelemahan (Weakness $(W)$ ) mahasiswanya kurang banyak, tidak ada sosialisasi Jurusan ke luar dengan mengambil peluang peluang (Opportunity (O)) merekrut mahasiswa sangat besar terlihat dari adanya peminat mahasiswa yang tinggi.

Selain strategi SO (Strenght, Opportunity) dan strategi WO (Weakness, Opportunity), adapula strategi ST (Strenght, Threat) dan WT (Weakness, Threat). Hasil analisis informasi dengan menggunakan matrik kekuatan - ancaman (Strenght - Threat), terbentuklah strategi ST (Strenght, Threat), a. Mengadakan kerjasama dengan Lembaga, Instansi, Perusahaan dan lainnya guna mendapatkan peluang kerja dan untuk mengembangkan Jurusan dengan cara memanfaatkan kekuatan dosen expert dan memiliki pengalaman yang baik di bidangnya, kredibilitas dosen sangat baik, untuk mengatasi ancaman minimnya kerjasama antara jurusan dengan lain, b. Mengadakan workshop kurikulum untuk memanfaatkan kekuatan kurikulum yang sangat bagus jika dibandingkan dengan kurikulum IPB untuk mengatasi ancaman persaingan dengan jurusan PMI pada Perguruan Tinggi Lain dan ancaman PMI kurang dikenal

Selain itu strategi ST (Strenght, Threat) lainnya yaitu, menambahkan tim pengajar untuk memanfaatkan kekuatan kurikulum sangat bagus jika dibandingkan dengan kurikulum IPB dalam rangka mengatasi ancaman persaingan dengan jurusan PMI Perguruan Tinggi Lain, d. Studi komparatif dengan Jurusan lainnya untuk memanfaatkan kekuatan kurikulum sangat bagus jika dibandingkan dengan kurikulum IPB dalam rangka mengatasi ancaman persaingan dengan jurusan PMI Perguruan Tinggi Lain, dan ancaman PMI kurang dikenal, e. Pengoptimalisasian Blog PMI untuk memanfaatkan kekuatan pelayanan selalu memberikan solusi dalam rangka mengatasi PMI yang kurang dikenal.

Strategi ST (Strenght, Threat) berikutnya adalah, f. Pembuatan Website agar lebih eksis untuk memanfaatkan kekuatan pelayanan selalu memberikan solusi dalam rangka mengatasi PMI yang kurang dikenal, g. Mengaktivasi Alumni untuk memfasilitasi pemberdayaan bagi mahasiswa memiliki desa binaan untuk memanfaatkan kurikulum yang sangat bagus jika dibandingkan dengan kurikulum IPB dalam rangka mengatasi ancaman persaingan dengan jurusan PMI Perguruan Tinggi Lain, dan ancaman PMI kurang dikenal.

Hasil analis informasi dengan menggunakan matrik kelemahan ancaman (Weakness - Threat), terbentuklah strategi WT (Weakness Threat), a. PMI mengabdi untuk Negeri dalam rangka meminimalisir kelemahan kurangnya kerjasama antara HMJ dengan Jurusan, minimnya kreativitas mahasiswa, motivasi mahasiswa rendah, dan kelemahan tidak ada sosialisasi Jurusan ke luar untuk mengatasi ancaman minimnya kerjasama antara jurusan dengan lain, persaingan dengan jurusan PMI Perguruan Tinggi Lain, dan ancaman PMI yang kurang dikenal.

Kemudian strategi WT (Weakness Threat) berikutnya yaitu, b. Study Tour's Comdev to Yogyakarta dalam rangka meminimalisir kelemahan kurangnya 
Urutan Rangking Strategi yang memiliki Daya Tarik berdasarkan Skor IFAS Hasil Analisis Pengambilan Keputusan Matrik Perencanaan Strategi Kuantitatif (The Quantitative Strategic Planning Matrix (QSPM)

\begin{tabular}{|c|c|c|c|c|}
\hline $\begin{array}{l}\text { No } \\
\text { Rangking }\end{array}$ & $\begin{array}{l}\text { No } \\
\text { Strate } \\
\text { gi }\end{array}$ & $\begin{array}{l}\text { Skor } \\
\text { IFAS }\end{array}$ & Strategi layak & Status \\
\hline 1 & 15 & 2,6 & $\begin{array}{l}\text { Memfasilitasi Mahasiswa dengan Workshop } \\
\text { social entrepreneur }\end{array}$ & Strategi Intensif \\
\hline 2 & 8 & 2,4 & Studi komparatif dengan Jurusan lainnya & Strategi Intensif \\
\hline 3 & 12 & 2,40 & Membuat kerjasama secara kesinambungan & Strategi Intensif \\
\hline 4 & 1 & 2,35 & $\begin{array}{l}\text { Mengadakan kerjasama dengan Lembaga, } \\
\text { Instansi, Perusahaan dan lainnya untuk } \\
\text { mendapatkan peluang kerja dan untuk } \\
\text { mengembangkan jurusan }\end{array}$ & Strategi Intensif \\
\hline 5 & 18 & 2,35 & PMI mengabdi untuk Negeri & Strategi Intensif \\
\hline 6 & 5 & 2,25 & $\begin{array}{l}\text { Mengadakan kerjasama dengan Lembaga, } \\
\text { Instansi, Perusahaan dan lainnya untuk } \\
\text { mendapatkan peluang kerja dan untuk } \\
\text { mengembangkan Jurusan }\end{array}$ & Strategi Intensif \\
\hline 7 & 3 & 2,21 & Diadakan pertukaran pelajar & Strategi Intensif \\
\hline 8 & 4 & 2,21 & melakukan pemberdayaan mahasiswa & Strategi Intensif \\
\hline 9 & 17 & 2,16 & ComDev Goes To School & Strategi Intensif \\
\hline 10 & 9 & 2,14 & Pengoptimalisasin Blog PMI & Strategi Intensif \\
\hline 11 & 10 & 2,14 & Pembuatan Website agar lebih eksis & Strategi Intensif \\
\hline 12 & 14 & 2,1 & $\begin{array}{l}\text { Pembuatan desa binaan yang dikelola oleh } \\
\text { Mahasiswa dan alumi PMI }\end{array}$ & Strategi Intensif \\
\hline 13 & 20 & 2 & $\begin{array}{l}\text { Merevitalisasi jurnal Nasional Jurusan PMI } \\
\text { Se-Indonesia }\end{array}$ & Strategi Intensif \\
\hline 14 & 6 & 1,93 & Mengadakan workshop kurikulum & Non Strategi Intensif \\
\hline 15 & 11 & 1,93 & $\begin{array}{l}\text { Mengaktivasi Alumni untuk memfasilitasi } \\
\text { pemberdayaan bagi mahasiswa memiliki desa } \\
\text { binaan }\end{array}$ & Non Strategi Intensif \\
\hline 16 & 2 & 1,86 & $\begin{array}{l}\text { Pemberian beasiswa terhadap mahasiswa } \\
\text { PMI }\end{array}$ & Non Strategi Intensif \\
\hline 17 & 16 & 1,85 & $\begin{array}{l}\text { Perlunya pertemuan Alumni dan Mahasiswa } \\
\text { serta Jurusan secara berkala }\end{array}$ & Non Strategi Intensif \\
\hline 18 & 13 & 1,8 & $\begin{array}{l}\text { Pelaksanaan intensif bahasa asing dengan } \\
\text { pusat bahasa UIN (sort course) }\end{array}$ & Non Strategi Intensif \\
\hline 19 & 19 & 1,70 & Study Tour's Comdev to Yogyakarta & Non Strategi Intensif \\
\hline 20 & 7 & 1,5 & Menambahkan tim pengajar & Non Strategi Intensif \\
\hline
\end{tabular}

Sumber; Hasil Analisis Pengambilan Keputusan Matrik Perencanaan Strategi Kuantitatif

(Quantitative Strategic Planning Matrix (QSPM))

penguasaan bahasa asing pada mahasiswa, dan kelemahan motivasi mahasiswa rendah untuk mengatasi ancaman persaingan dengan jurusan PMI pada Perguruan Tinggi Lain, c. Merevitalisasi jurnal Nasional Jurusan PMI Se-Indonesia dalam rangka meminimalisir kelemahan minimnya kreativitas mahasiswa, sarana dan prasarana kurang banyak (Pustaka dan kelas), dan kelemahan mahasiswanya kurang banyak untuk mengatasi ancaman PMI kurang dikenal.

Sebelum mengetahui posisi Jurusan PMI Fakultas Dakwah dan Ilmu Komunikasi (FIDKOM) UIN Syarif Hidayatullah Jakarta di tahun 2017 dengan menggunakan Matrik 
Internal-Eksternal (Internal-External (IE) Matrix), terlebih dahulu dilakukan analisis Faktor Strategi Internal (Internal Strategic Factor Analisis Summary (IFAS) dan analisis Faktor Strategi Eksternal (External Strategic Factor Analisis Summary (EFAS).

Hasil penghitungan IFAS bobot tertinggi untuk yang paling penting adalah metode mengajar dosen menarik, dan kurikulum sangat bagus jika dibandingkan dengan kurikulum IPB, dengan bobot 0,155. Sementara bobot terendah atau untuk yang paling tidak penting adalah kurangnya kerjasama antara HMJ dengan Jurusan, mahasiswanya kurang banyak, dan tidak ada sosialisasi Jurusan ke luar dengan bo6ot 0,025 .

Sementara itu untuk penghitungan IFAS rating tertinggi atau yang paling baik adalah metode mengajar dosen menarik, dan kurikulum sangat bagus jika dibandingkan dengan kurikulum IPB dengan rating 4. Sementara rating terendah atau yang paling buruk adalah sarana dan prasarana kurang banyak (pustaka dan kelas), mahasiswanya kurang banyak dengan rating 1.

Pada penghitungan EFAS bobot tertinggi untuk yang paling penting adalah alumni dapat bekerja di berbagai sektor, instansi, LSM baik yang pemberdayaan maupun yang bukan emberdayaan serta dapat mendirikan lembaga sendiri dengan bobot 0,3 . Sementara bobot terendah atau untuk yang paling tidak penting adalah minimnya kerjasama antara jurusan dengan jurusan lain dengan bobot 0,05.

Sementara itu untuk penghitungan EFAS rating tertinggi atau yang paling baik adalah Alumni dapat bekerja di berbagai sektor, instansi, LSM baik yang pemberdayaan maupun yang bukan pemberdayaan serta dapat mendirikan lembaga sendiri, banyaknya peluang kerjasama dengan lembaga lain, persaingan dengan jurusan PMI Perguruan Tinggi lain dengan rating 4 . Sementara rating terendah atau yang paling buruk adalah minimnya kerjasama antara jurusan dengan jurusan lain, dan PMI kurang dikenal dengan rating 1.

Skor Faktor Strategi Internal (Internal Strategic Factor Analisis Summary (IFAS)) sebesar 2,79 sementara itu skor Faktor Strategi Eksternal (External Strategic Factor Analisis Summary (EFAS)) sebesar 3,45 . Skor tersebut dijadikan sebagai data untuk mengisi matrik Internal dan Eksternal (Internal-External (IE) Matrix). Skor EFAS sebesar 3,45 diletakkan pada titik tengah-tengah antara angka 3 dan 4 pada sumbu $\mathrm{Y}$ atau sumbu yang berada pada garis lurus ke atas atau vertikal. Berbeda dengan skor IFAS sebesar 2,79 diletakkan pada titik 3/4 antara angka 2 dan 3.pada sumbu $\mathrm{X}$ atau sumbu yang berada pada garis melintang ke samping atau horizontal. Kemudian keduanya ditarik garis hingga keduannya bertemu, dengan demikian hasilnya berada di kuadran II.

Nilai titik pada kuadran II menunjukan posisi jurusan PMI Fidkom UIN Syarif Hidayatullah Jakarta dalam keadaan tumbuh/pertumbuhan. David menyatakan ${ }^{16}$, ada beberapa catatan yang harus diperhatikan untuk wilayah kuadran II yaitu, melakukan evaluasi pasar meskipun dalam posisi tumbuh/berkembang yaitu dengan memunculkan beberapa pertanyaan 
misalnya saja mengapa pendekatan perusahaan tidak efektif dan bagaimana cara mengubahnya agar dapat meningkatkan daya saing.

Berkaitan hal itu, posisi jurusan PMI Fidkom UIN Syarif Hidayatullah berada di Kuadran II menunjukkan bahwa meskipun dalam kondisi tumbuh dan berkembang, namun jurusan PMI Fidkom berada pada lingkungan persaingan yang cepat, sehingga disarankan segera lakukan strategi intensif.

David menjelaskan pula ${ }^{17}$, strategi intensif ada dua macam pertama penetrasi pasar (Market Penetration) dan Pengembangan pasar (Market Development). Strategi penetrasi pasar berusaha meningkatkan pangsa pasar yang ada melalui promosi dan publisitas yang terus menerus. Pengembangan pasar yaitu upaya memperkenalkan produk atau jasa yang ada ke wilayah yang baru.

Jika dikaitkan dengan kondisi Jurusan PMI, maka Jurusan PMI dapat melakukan strategi intensif dengan cara mengadakan promosi dan publikasi mengenai jurusan, prestasi mahasiswa, serta pelayanan yang prima, dan publikasi secara gencar untuk meningkatkan pangsa pasar baik ke wilayah yang ada maupun ke wilayah baru.

Pada tahap pegambilan keputusan akan terbentuk strategi yang memiliki daya tarik tertinggi hingga terendah dengan menggunakan Matrik Perencanaan Strategi Kuantitatif (Quantitative Strategic Planning Matrix (QSPM)). Standar yang akan digunakan yaitu apakah kekuatankelemahan-peluang-ancaman (StrenghtWeakness-Opportunity-Threat) berpengaruh terhadap tiap-tiap strategi yang layak?
Pengambilan keputusan dengan menggunakan Matrik Perencanaan Strategi Kuantitatif (Quantitative Strategic Planning Matrix (QSPM)) untuk menentukan strategi yang paling tinggi hingga paling rendah daya tariknya. Alternatif Strategi diwakilkan dengan angka. Strategi layak yang ditandai dengan angka 1 adalah, mengadakan kerjasama dengan Lembaga, Instansi, Perusahaan dan lainnya untuk mendapatkan peluang kerja dan untuk mengembangkan jurusan, angka 2. Pemberian beasiswa terhadap mahasiswa PMI, 3. Diadakan pertukaran pelajar, 4. melakukan pemberdayaan mahasiswa, 5 . Mengadakan kerjasama dengan Lembaga, Instansi, Perusahaan dan lainnya untuk mendapatkan peluang kerja dan untuk mengembangkan Jurusan.

Skor total tertinggi pada analisis IFAS terletak pada nomor/angka 1 yaitu, strategi layak mengadakan kerjasama dengan Lembaga, Instansi, perusahaan dan lainnya untuk mendapatkan peluang kerja dan untuk mengembangkan jurusan. Sedangkan skor total terendahnya adalah terletak pada nomor 5, strategi pemberian beasiswa terhadap mahasiswa PMI.

Skor total tertinggi pada analisis EFAS terletak pada nomor 5 yaitu, strategi layak Mengadakan kerjasama dengan Lembaga, Instansi, Perusahaan dan lainnya untuk mendapatkan peluang kerja dan untuk mengembangkan Jurusan. Sedangkan skor total terendahnya terletak pada nomor 2, strategi pemberian beasiswa terhadap mahasiswa PMI.

Strategi layak ditandai dengan angka 6 adalah, mengadakan workshop kurikulum, 7. Menambahkan tim pengajar, 8. Studi 
Tabel 2

Urutan Rangking Strategi yang memiliki Daya Tarik berdasarkan Skor EFAS Kuantitatif

Hasil Analisis Pengambilan Keputusan Matrik Perencanaan Strategi

(The Quantitative Strategic Planning Matrix (QSPM))

\begin{tabular}{|c|c|c|c|c|}
\hline $\begin{array}{l}\text { No } \\
\text { Rangkin } \\
\text { g }\end{array}$ & $\begin{array}{l}\text { No } \\
\text { Strategi }\end{array}$ & $\begin{array}{l}\text { Skor } \\
\text { IFAS }\end{array}$ & Strategi layak & Status \\
\hline 1 & 10 & 3,63 & Pembuatan Website agar lebih eksis & Strategi Intensif \\
\hline 2 & 5 & 3,6 & $\begin{array}{l}\text { Mengadakan kerjasama dengan Lembaga, } \\
\text { Instansi, Perusahaan dan lainnya untuk } \\
\text { mendapatkan peluang kerja dan untuk } \\
\text { mengembangkan Jurusan }\end{array}$ & Strategi Intensif \\
\hline 3 & 9 & 3,6 & Pengoptimalisasin Blog PMI & Strategi Intensif \\
\hline 4 & 12 & 3,6 & $\begin{array}{lll}\text { Membuat } & \text { kerjasama } & \text { secara } \\
\text { kesinambungan } & & \end{array}$ & Strategi Intensif \\
\hline 5 & 14 & 3,6 & $\begin{array}{l}\text { Pembuatan desa binaan yang dikelola oleh } \\
\text { Mahasiswa dan alumi PMI }\end{array}$ & Strategi Intensif \\
\hline 6 & 11 & 3,5 & $\begin{array}{l}\text { Mengaktivasi Alumni untuk memfasilitasi } \\
\text { pemberdayaan bagi mahasiswa memiliki } \\
\text { desa binaan }\end{array}$ & Strategi Intensif \\
\hline 7 & 17 & 3,4 & ComDev Goes To School & Strategi Intensif \\
\hline 8 & 15 & 3,3 & $\begin{array}{lrl}\text { Memfasilitasi } & \text { Mahasiswa } & \text { dengan } \\
\text { Workshop social entrepreneur } & \end{array}$ & Strategi Intensif \\
\hline 9 & 18 & 3,3 & PMI mengabdi untuk Negeri & Strategi Intensif \\
\hline 10 & 20 & 3,3 & $\begin{array}{l}\text { Merevitalisasi jurnal Nasional Jurusan } \\
\text { PMI Se-Indonesia }\end{array}$ & Strategi Intensif \\
\hline 11 & 1 & 3,25 & $\begin{array}{l}\text { Mengadakan kerjasama dengan Lembaga, } \\
\text { Instansi, Perusahaan dan lainnya untuk } \\
\text { mendapatkan peluang kerja dan untuk } \\
\text { mengembangkan jurusan }\end{array}$ & Strategi Intensif \\
\hline 12 & 4 & 3,1 & Melakukan pemberdayaan mahasiswa & Strategi Intensif \\
\hline 13 & 13 & 3,1 & $\begin{array}{l}\text { Pelaksanaan intensif bahasa asing dengan } \\
\text { pusat bahasa UIN (sort course) }\end{array}$ & Non Strategi Intensif \\
\hline 14 & 3 & 3 & Diadakan pertukaran pelajar & Non Strategi Intensif \\
\hline 15 & 6 & 2,9 & Mengadakan workshop kurikulum & Non Strategi Intensif \\
\hline 16 & 16 & 2,7 & $\begin{array}{l}\text { Perlunya pertemuan Alumni dan } \\
\text { Mahasiswa serta Jurusan secara berkala }\end{array}$ & Non Strategi Intensif \\
\hline 17 & 7 & 2,5 & Menambahkan tim pengajar & Non Strategi Intensif \\
\hline 18 & 8 & 2,5 & Studi komparatif dengan Jurusan lainnya & Non Strategi Intensif \\
\hline 19 & 2 & 2,3 & $\begin{array}{l}\text { Pemberian beasiswa terhadap mahasiswa } \\
\text { PMI }\end{array}$ & Non Strategi Intensif \\
\hline 20 & 19 & 1,9 & Study Tour's Comdev to Yogyakarta & Non Strategi Intensif \\
\hline
\end{tabular}

Sumber; Hasil Analisis Pengambilan Keputusan Matrik Perencanaan Strategi Kuantitatif (Quantitative

Strategic Planning Matrix (QSPM)).

komparatif dengan Jurusan lainnya, 9.

Skor total tertinggi pada analisis IFAS Pengoptimalisasin Blog PMI, dan 10. tereletak pada nomor 8 yaitu, strategi layak Pembuatan Website agar lebih eksis. Studi komparatif dengan Jurusan lainnya. 
Sedangkan skor total terendahnya terletak pada nomor 5 , strategi Menambahkan tim pengajar.

Skor total tertinggi pada analisis EFAS terletak pada nomor 10 yaitu, strategi layak Pembuatan Website agar lebih eksis. Sedangkan skor total terendahnya terletak pada nomor 7 , strategi Menambahkan tim pengajar dan nomor 8, Studi komparatif dengan Jurusan.

Strategi layak yang ditandai dengan angka 11 adalah, Mengaktivasi Alumni untuk memfasilitasi pemberdayaan bagi mahasiswa memiliki desa binaan, 12. Membuat kerjasama secara kesinambungan, 13. Pelaksanaan intensif bahasa asing dengan pusat bahasa UIN (sort course), 14. Pembuatan desa binaan yang dikelola oleh Mahasiswa dan alumi PMI, dan 15. Memfasilitasi Mahasiswa dengan Workshop social entrepreneur.

Skor total tertinggi pada analisis IFAS terletak pada strategi nomor 15 yaitu, strategi layak Memfasilitasi Mahasiswa dengan Workshop social entrepreneur. Sedangkan skor total terendahnya terletak pada nomor 13, strategi Pelaksanaan intensif bahasa asing dengan pusat bahasa UIN (sort course).

Skor total tertinggi pada analisis EFAS terletak pada nomor 12 Membuat kerjasama secara kesinambungan, dan 14 yaitu, strategi Pembuatan desa binaan yang dikelola oleh Mahasiswa dan alumi PMI. Sedangkan skor total terendahnya terletak pada nomor 13, strategi Pelaksanaan intensif bahasa asing dengan pusat bahasa UIN (sort course).

Strategi layak yang ditandai dengan angka 16 adalah, Perlunya pertemuan
Alumni dan Mahasiswa serta Jurusan secara berkala, 17. ComDev Goes To School, 18. PMI mengabdi untuk Negeri, 19. Study Tour's Comdev to Yogyakarta, dan 20. Merevitalisasi jurnal Nasional Jurusan PMI Se-Indonesia.

Skor total tertinggi pada analisis IFAS terletak pada strategi nomor 18 yaitu, strategi layak PMI mengabdi untuk Negeri. Sedangkan skor total terendahnya terletak pada nomor 19, strategi Study Tour's Comdev to Yogyakarta.

Skor total tertinggi pada analisis EFAS terletak pada nomor 17 ComDev Goes To School. Sedangkan skor total terendahnya terletak pada nomor 19, strategi Merevitalisasi jurnal Nasional Jurusan PMI Se-Indonesia.

Strategi daya tertinggi hasil analisis IFAS pada tabel 1 dari nomor rangking 1 sampai dengan 13 dari 20 strategi yang ada, merupakan strategi intensif karena berisi tentang strategi yang meningkatkan pangsa pasar dengan cara promosi secara gencar.

Sedangkan pada tabel 2, maka nampak bahwa strategi daya tertinggi hasil analisis EFAS dari nomor rangking 1 sampai dengan 12 dari 20 strategi yang ada, merupakan strategi intensif karena berisi tentang strategi yang meningkatkan pangsa pasar dengan cara promosi secara gencar.

Berdasarkan kedua tabel tersebut (tabel 16 dan tabel 17) maka Hal ini sesuai dengan hasil analisis informasi kondisi Jurusan PMI Fidkom UIN Syarif Hidayatullah Jakarta. Pada analisis informasi kondisi Jurusan PMI berada di Kuadran II atau sedang mengalami pertumbuhan dan perkembangan. 
Namun Jurusan PMI berada pada lingkungan persaingan yang kuat sehingga dengan kondisi yang demikian (pada kuadran II), PMI disarankan menjalankan strategi intensif atau strategi yang berupaya meningkatkan pangsa pasar dengan melakukan promosi prestasi Mahasiswa, pelayanan yang prima, kurikulum yang baik, dengan secara gencar baik kepada wilayah yang ada maupun wilayah yang baru.

\section{KESIMPULAN}

Strategi yang layak digunakan oleh Jurusan PMI Fidkom UIN Syarif Hidayatullah Jakarta dalam menghadapi MEA (Masyarakat Ekonomi Asean) dengan menggunakan Kerangka Analisis Penyusunan Strategi (The StrategyFormulation Analytical Framework) terdiri dari strategi memanfaatkan kekuatan untuk mengambil peluang (Strenght-Opportunity (SO)), memanfaatkan kekuatan untuk mengatasi ancaman (Strenght-Threat(ST)), meminimalisir kelemahan untuk mengambil peluang (WeaknessOpportunity (WO)), dan memiminimalisir kelemahan untuk mengatasi ancaman (Weakness-Threat(WT).

Strategi memanfaatkan kekuatan dan mengambil peluang (Strenght-Opportunity (SO)) yaitu, Mengadakan kerjasama dengan Lembaga, Instansi, Perusahaan dan lainnya untuk mendapatkan peluang kerja dan untuk mengembangkan jurusan, Pemberian beasiswa terhadap mahasiswa PMI, Diadakan pertukaran pelajar, melakukan pemberdayaan mahasiswa.

Strategi memanfaatkan kekuatan untuk mengatasi ancaman (Strenght-Threat (ST)) yaitu, Mengadakan kerjasama dengan
Lembaga, Instansi, Perusahaan dan lainnya untuk mendapatkan peluang kerja dan untuk mengembangkan Jurusan, Mengadakan workshop kurikulum, Menambahkan tim pengajar, Studi komparatif dengan Jurusan lainnya, Pengoptimalisasin Blog PMI, Pembuatan Website agar lebih eksis, dan Mengaktivasi Alumni untuk memfasilitasi pemberdayaan bagi mahasiswa memiliki desa binaan.

Strategi meminimalisir kelemahan untuk mengambil peluang (WeaknessOpportunity (WO)) yaitu, Membuat kerjasama secara kesinambungan, Pelaksanaan intensif bahasa asing dengan pusat bahasa UIN (sort course), Pembuatan desa binaan yang dikelola oleh Mahasiswa dan alumi PMI, Memfasilitasi Mahasiswa dengan Workshop social entrepreneur, Perlunya pertemuan Alumni dan Mahasiswa serta Jurusan secara berkala, ComDev Goes To School, Strategi meminimalisir kelemahan untuk mengambil peluang (Weakness-Threat (WT)), PMI mengabdi untuk Negeri, Study Tour's Comdev to Yogyakarta, Merevitalisasi jurnal Nasional Jurusan PMI Se-Indonesia.

Posisi Jurusan PMI Fidkom UIN Syarif Hidayatullah Jakarta saat ini berada di Kuadran II menunjukkan bahwa meskipun dalam kondisi tumbuh dan berkembang, namun jurusan PMI Fidkom berada pada lingkungan persaingan yang cepat, sehingga disarankan segera lakukan strategi intensif.

Strategi yang memiliki daya tarik dari yang tertinggi hingga yang terendah yang dapat digunakan oleh Jurusan PMI Fidkom UIN Syarif Hidayatullah Jakarta dalam menghadapi MEA (Masyarakat Ekonomi 
Asean) dengan menggunakan Kerangka Analisis Penyusunan Strategi (The StrategyFormulation Analytical Framework) ada 15 rangking yang memiliki nilai strategi intensif.

$$
\text { Strategi Intensifnya yaitu, }
$$

Memfasilitasi Mahasiswa dengan Workshop social entrepreneur, Studi komparatif dengan Jurusan lainnya, Membuat kerjasama secara kesinambungan, Mengadakan kerjasama dengan Lembaga, Instansi, Perusahaan dan lainnya untuk mendapatkan peluang kerja dan untuk mengembangkan jurusan, PMI mengabdi untuk Negeri, Mengadakan kerjasama dengan Lembaga, Instansi, Perusahaan dan lainnya untuk mendapatkan peluang kerja dan untuk mengembangkan Jurusan, Diadakan pertukaran pelajar, Melakukan pemberdayaan mahasiswa, ComDev Goes To School, Pengoptimalisasin Blog PMI, Pembuatan Website agar lebih eksis, Pembuatan desa binaan yang dikelola oleh Mahasiswa dan alumi PMI, Merevitalisasi jurnal Nasional Jurusan PMI Se-Indonesia, Mengaktivasi Alumni untuk memfasilitasi pemberdayaan bagi mahasiswa memiliki desa binaan.

Berdasarkan strategi yang memiliki daya tarik yang dihasilkan pada penelitian ini yaitu berupa strategi intensif, ternyata sesuai dengan hasil analisis informasi kondisi Jurusan PMI Fidkom UIN Syarif Hidayatullah Jakarta yang disarankan menggunakan strategi intensif. Pada analisis informasi kondisi Jurusan PMI berada di Kuadran II atau sedang mengalami pertumbuhan dan perkembangan.
Namun Jurusan PMI berada pada lingkungan persaingan yang kuat sehingga dengan kondisi yang demikian (pada kuadran II), PMI diharapkan menjalankan strategi intensif atau strategi yang berupaya meningkatkan pangsa pasar dengan melakukan promosi prestasi Mahasiswa, pelayanan yang prima, kurikulum yang baik, dengan secara gencar baik kepada wilayah yang ada maupun wilayah yang baru terutama di kawasan ASEAN untuk menghadapai MEA/EAC di masa mendatang.

Hasil penelitian ini sesuai pula dengan Jurusan PMI Fidkom UIN Syarif Hidayatullah yang telah memiliki kurikulum yang baik yang telah diakui oleh kemensos dengan organisasi APSI (Asosiasi Pembangunan Sosial Indonesia). Harapannya Mahasiswa Jurusan PMI Fidkom UIN Syarif Hidayatullah Jakarta dapat menjadi bagian dari tenaga kerja Indonesia yang siap yang menyebar di seluruh Negara ASEAN dengan bermodalkan kemampuan bahasa inggris yang diperoleh selama dua semester dengan sks masing-masing 4 total menjadi 8 , serta sertifikat lulus TOEFL dengan batas skor minimal $400^{18}$, memiliki skill sebagai pengembangan masyarakat baik di bidang ekonomi maupun di bidang lainnya.

Kemampuan mengembangkan masyarakat berbasis ekonomi alumni diperoleh dari materi perkuliahan yang terdistribusikan dalam mata kuliah seperti mata kuliah Manajemen Lembaga Keuangan Ummat Manajemen Community Organizer, Pengembangan Kelembagaan Lokal, Pengembangan UKM dan Koperasi, 
Kewirausahaan, Pengantar Manajemen, dan Pengantar Ekonomi ${ }^{19}$.

Berdasarkan posisi Jurusan PMI Fidkom UIN Syarif Hidayatullah Jakarta yang berada di posisi sedang pertumbuhan atau berkembang maka tidak diperlukan perubahan nama menjadi Program Studi Pembangunan. Namun cukup melakukan strategi intensif yaitu dengan mengupayakan meningkatkan pangsa pasar dengan melalukan promosi secara gencar di Wilayah yang ada maupun di Wilayah yang baru terutama kawasan ASEAN. Dengan demikian diharapkan Jurusan PMI Fidkom UIN Syarif Hidayatullah dapat menghadapi MEA/EAC di masa mendatang. 


\section{Catatan Akhir}

${ }^{1}$ www.bbc.com/Indonesia/berita indonesia /2014/08/140826_pasar_tenaga_kerja-aec

2 Borang Program Studi Pengembangan Masyarakat Islam Fakultas IImu Dakwah dan IImu Komunikasi UIN Syarif Hidayatullah Jakarta, th. 2015/2016, hal 6 .

3 Fred R. David, 2011, Strategic Management Concepts and cases Thirteenth edition, Prentice Hall p. 164

4 Michael A. Hitt etc, Strategic Management Consepts \& Cases Competitiveness and Globalization $8^{\text {th }}$ edition, 2010, South-Western Cengage Learning USA 2010, p. 4.

${ }^{5}$ Fred R. David, 2011, Strategic Management Concepts and cases Thirteenth edition, Prentice Hall p. 177.

6 Fred R. David, 2011, Strategic Management Concepts and cases Thirteenth edition, Prentice Hall p. 178.

7 Freddy Rangkuti, 2004, Analisis SWOT Teknik Membedah Kasus Bisnis Reorientasi Konsep Perencanaan Strategis untuk Menghadapi Abad 21, PT. Gramedia Pustaka Utama, 2004, Jakarta, hal. 42.

${ }^{8}$ Freddy Rangkuti, 2004, Analisis SWOT Teknik Membedah Kasus Bisnis Reorientasi Konsep Perencanaan Strategis untuk Menghadapi Abad 21, PT. Gramedia Pustaka Utama, Jakarta, hal. 136-137.

${ }^{9}$ Fred R. David, 2011, Strategic Management Concepts and cases Thirteenth edition, Prentice Hall p. 192.

${ }^{10}$ Asean Economic Blueprint, 2008, Association of Southeast Asian Nations, p. 6-7.

${ }^{11}$ Asean Economic Blueprint, 2008, Association of Southeast Asian Nations, p. 16-17.

12 Understanding the ASEAN Economic Community (AEC)-Frequently Asked Questions, 2014, The U.S. Commercial Service - Your Gateway to ASEAN

13 The ASEAN Secretariat Jakarta, 2015, Asean Economic Community Blueprint 2025, Public Outreach and Civil Society Division, p. 7

14 Visi, Misi, Tujuan, dan Sasaran serta Strategi Pencapaian, Borang PMI Fidkom UIN Syarif Hidayatullah Jakarta, tahun 2015, h. 5
15 Standar 5 Kurikulum, Pembelajaran, dan Suasana Akademik, Borang PMI Fidkom UIN Syarif Hidayatullah Jakarta, tahun 2015, h. 95-96

16 Fred R. David, 2011, Strategic Management Concepts and cases Thirteenth edition, Prentice Hall p. 192.

${ }^{17}$ Fred R. David, 2009, Manajemen Strategis, Salemba Empat Jakarta, hal. 252-272.

18 Standar 5 Kurikulum, Pembelajaran, dan Suasana Akademik, Borang PMI Fidkom UIN Syarif Hidayatullah Jakarta, tahun 2015, h. 95

19 Standar 5 Kurikulum, Pembelajaran, dan Suasana Akademik, Borang PMI Fidkom UIN Syarif Hidayatullah Jakarta, tahun 2015, h. 95-96

www.bbc.com/Indonesia/berita ind onesia/2014/08/140826 pasar tenaga kerja-aec 


\section{DAFTAR PUSTAKA}

Association of Southeast Asian Nations. 2008. Asean Economic Community Blueprint. Jakarta: ASEAN Secretary.

Prodi Pengembangan Masyarakat Islam. 2016. Borang Program Studi Pengembangan Masyarakat Islam Fakultas Ilmu Dakwah dan Ilmu Komunikasi UIN Syarif Hidayatullah Jakarta th. 2015/2016. Jakarta: Program Studi Pengembangan Masyarakat Islam Filmu Dakwah dan Komunikasi UIN Syarif Hidayatullah Jakarta.

David, Fred R. 2009. Manajemen Strategis. Jakarta: Salemba Empat.

David, Fred R. 2011. Strategic Management Concepts and cases Thirteenth edition. USA: Prentice Hall.

Michael A. Hitt etc. 2010. Strategic Management Consepts \& Cases Competitiveness and Globalization $8^{\text {th }}$ edition. USA: South-Western Cengage Learning USA.

Rangkuti, Fredy. 2002. Analisis SWOT Teknik Membedah Kasus Bisnis Reorientasi Konsep Perencanaan Strategis untuk Menghadapi Abad 21. Jakarta: PT. Gramedia Pustaka Utama. Prodi Pengembangan Masyarakat Islam. 2015. Standar 5 Kurikulum, Pembelajaran, dan Suasana
Akademik. Jakarta: Borang PMI Fidkom UIN Syarif Hidayatullah Jakarta.

The ASEAN Secretariat Jakarta. 2015. Asean Economic Community Blueprint 2025. Jakarta: Public Outreach and Civil Society Division.

Thomas L. Wheelen and J. David Hunger. 2012. Strategic Management and Business Policy Toward Global Sustainability Thirteenth Edition. United Soutes of America : Publishing as Prentice Hall.

Your Gateway to ASEAN Departement of Committe. Understanding the ASEAN Economic Community (AEC)Frequently Asked Questions. 2014. United Soutes of America : The U.S. Commercial Service.

Hitt, Michael A. et.all. Strategic Management Concept \& Cases Competitiveness and Globalization $8^{\text {th }}$. Canada : Edition. South-Western Cengage Learning. 